\title{
Changing Patient Perceptions of MTM: Determining an Effective Method of Education
}

\author{
Lindsay Mailloux, BSPS, PharmD Candidate 2018; Samantha Yates, BSPS, PharmD Candidate 2018; Kristin Spencer, BSPS, PharmD
} Candidate 2018; Jacob Davis, BSPS, PharmD Candidate 2018; Aleda M.H. Chen, PharmD, MS, PhD; Thaddeus Franz, PharmD

Cedarville University School of Pharmacy

\begin{abstract}
Background: Medication Therapy Management (MTM) is a vital resource in reducing medication nonadherence, yet many individuals who are eligible for MTM services are unaware of what MTM is and how to enroll. Little is known about how to best educate patients on MTM services and its benefits. Objective: To determine the difference between in-person education community education versus brochure community education on MTM services on perceptions of and enrollment in MTM services. Methods: A pre-post quasi experimental study, where patients were allocated to receive information about MTM through an educational brochure or an in-person education session and completed survey assessments pre-and post-intervention, was conducted at a federally-qualified health center. Patients who were ages 18 years or older, MTM-eligible, and had received no prior MTM service were eligible to participate. Changes in patient perceptions of and enrollment in MTM from pre-to post-intervention were assessed by survey instruments developed for this study. Results: A total of 35 patients (brochure=25, in-person=10) were recruited for this study. Most participants (94.2\%) either reported having never heard of MTM or not being sure if they had heard of MTM. There were no significant between-group differences on pre-survey questions or pre-post within-group changes ( $p>0.05)$. There were significant between-group differences on 11 postassessment questions and MTM enrollment $(p<0.05)$, with the in-person education group showing improved perceptions and greater enrollment. Conclusion: Patients remain largely unaware of MTM services; there is a need for education to increase awareness. Even though educating patients in a face-to-face context had a more positive impact on perceptions of MTM and enrollment in MTM, more research is needed regarding the best educational methods as it was difficult for patients to find time to attend an educational session.
\end{abstract}

Keywords: Medication Therapy Management, Patient Education, Community Pharmacy

\section{INTRODUCTION}

Medication nonadherence, "the number of doses not taken or taken incorrectly that jeopardizes the patient's therapeutic outcome," ${ }^{11}$ is a problem that affects all ages and ethnic groups. Many patients may struggle with "not having a prescription filled, taking an incorrect dose, taking a medication at the wrong time, forgetting to take doses, or stopping therapy too soon," ${ }^{1}$ leading to non-adherence. Nonadherence is not limited to medication therapy alone, but could include lifestyle changes and nonpharmacologic treatments, such as exercise, smoking cessation, physical therapy and dietary plans. However, medication nonadherence remains a major public health concern and is referred to as an "invisible epidemic." Approximately $43 \%$ of the general population, $55 \%$ of the elderly population, and $54 \%$ of children and teenagers are nonadherent to their medications. ${ }^{1}$

Corresponding author: Aleda M.H. Chen, PharmD, MS, PhD Assistant Dean and Associate Professor of Pharmacy Practice Cedarville University School of Pharmacy

251 North Main St., Cedarville, OH 45314

Email: amchen@cedarville.edu

http://z.umn.edu/INNOVATIONS
Medication nonadherence has a large impact on health care costs. For example, it often furthers disease complications, causing an increase in costs due to increased medical appointments and hospitalizations. Each year, medication adherence issues contribute to nearly 125,000 deaths in the United States. ${ }^{2}$ Non adherence to medications is also responsible for up to $69 \%$ of medication-related admissions. ${ }^{2}$ Medical costs, whether direct or indirect, resulting from medication nonadherence have been estimated to be between $\$ 100$ billion to $\$ 300$ billion annually. ${ }^{2}$ With the number of Americans suffering from a chronic health condition projected to grow from 133 million people to 157 million people by the year 2020, there is a pressing need to find a solution to medication nonadherence. ${ }^{2}$

Researchers have found that factors of medication nonadherence fall into two broad categories: patient beliefs about their medication and practical barriers. The first category includes patients' perceptions about the risks, benefits, and efficacy of their medication formed by various influences such as personal experience, relationships, and communication with healthcare providers. $^{3}$ Patients must believe they actually have a disease and are susceptible to its consequences and also believe the recommended therapy will reduce the risks of their condition in order for them to be

$\begin{array}{lcc}\text { http://z.umn.edu/INNOVATIONS } & \text { 2018, Vol. 9, No. 2, Article } 3 & \text { INNOVATIONS in pharmacy } \\ & \text { DOI: https://doi.org/10.24926/iip.v9i2.990 }\end{array}$


adherent. ${ }^{4}$ Adherence decreases if these beliefs are not established with the aid of proper communication with healthcare providers.

Practical barriers include side effects, number of medications, frequency of dosing, complexity of therapy, and cost. $^{3}$ Research shows that a decline in socioeconomic status, increased duration of treatment, number of medications, frequency of dosing, and cost are all associated with decreased adherence. ${ }^{5,6}$ Patients who take medications for shorter periods of time tend to have greater adherence, whereas those patients on long-term or complicated therapy regimens have decreased adherence. ${ }^{4,7}$ Increased cost of medication leads to decreased adherence especially in patients with low income or low insurance coverage for prescription medications. ${ }^{8}$ Other factors such as demographics and disease state have also been considered as factors for non-adherence but have generally been found to be poor predictors of compliance. ${ }^{4}$ Much of the patient belief and practical barriers that inhibit medication adherence can be addressed through a medication therapy management (MTM) service, which "optimizes therapeutic outcomes for individual patients." 9

MTM services include a broad range of professional activities and responsibilities within the scope of pharmacy practice in a face-to-face setting or over the phone, provided by a pharmacist or other qualified healthcare professional. ${ }^{9}$ MTM includes services such as comprehensive medication reviews (CMR), medication action plans, and immunizations. Since MTM services became reimbursable as a part of Medicare Part D after the Medicare Modernization Act in 2004, pharmacists have made a significant impact on the problem of medication nonadherence. ${ }^{10,11}$ Indeed, one of the major goals of the provision for MTM under Medicare Part D was to improve patient medication adherence. ${ }^{12}$ Various studies support the finding that MTM services decrease patient medication nonadherence. A randomized controlled trial showed that the MTM intervention group had a higher rate of adherence and higher percentage of individuals who took their medication on time when compared to the usual care group. ${ }^{13}$ In addition, a retrospective cohort showed improvements in medication adherence for patients taking medications for various chronic conditions. ${ }^{14}$ Finally, a review of randomized controlled trials concluded, "The provision of MTM services by a pharmacist within a primary care medical home model can improve medication use in an ambulatory care setting." ${ }^{15}$ A primary care medical home has been defined as "a model of care in which the primary care provider coordinates the services provided by multiple health care providers, including pharmacy services, for patients." 15 With this evidence, it is reasonable to conclude that MTM is a vital resource in the effort to reduce medication nonadherence.
Despite the significant evidence of the potential benefits of MTM and its impact on medication nonadherence, many of those individuals eligible for MTM services are not aware of MTM and are not being referred by healthcare providers. In a study conducted to explore the awareness of Medicare Part D enrollees regarding MTM, researchers examined patients' expectations and perceptions of pharmacists in providing MTM. It was found that $93 \%$ of participants were unaware of MTM services, and $70 \%$ of respondents did not believe they needed MTM services. ${ }^{16}$ Another study determined patients' perceptions and expectations about the core elements of an MTM service in the community pharmacy setting. This study attempted to develop educational strategies and outreach programs that were aimed at increasing patients' knowledge of MTM services and the expanded role of pharmacists in the community pharmacy setting. Results showed that $60 \%$ of participants had never heard of MTM services, and patients had very limited knowledge of the core elements of an MTM service in the community pharmacy setting. ${ }^{17}$

Little is known on how to best educate patients on MTM services and its benefits in order to improve perceptions of and enrollment in MTM. Some research has also recently targeted their outcomes at discovering which method of communication (telephone, face-to-face, "bag-stuffer," or mailed letter) is more effective at enrolling a patient in an MTM session. While the researchers found no significant difference between their methods of communication, they did find that the majority of patients who agreed to have an MTM appointment were in the telephone group. The group that received a "bag stuffer" with information about MTM saw no response. ${ }^{18}$ Thus, the purpose of this project was to determine the most beneficial method of educating patients about MTM services and which method increases enrollment the most. An educational event was planned with the intent of creating a face-to-face opportunity for patients to learn more about what MTM services entail, interact with that information by asking questions, and enroll in an MTM session if desired. A brochurestyle approach was chosen as the other intervention to provide patients with a more convenient method (less time-intensive) of obtaining information about MTM services. The objectives were to determine the effect that different types of community education (brochure versus in-person education) on MTM services have on (1) perceptions of MTM services and (2) enrollment in MTM services.

\section{METHODOLOGY}

A pre-post quasi-experimental study was conducted to measure patient perceptions of MTM services and their enrollment in an MTM service before and after an educational intervention. Two different educational interventions were used for purposes of comparison. One intervention used was an interactive educational event (hereafter called in-person 
education), while the other intervention was an informational brochure (hereafter called brochure) distributed by mail. Cedarville University Institutional Review Board approval was obtained prior to the study.

Participants were recruited from the Rocking Horse Center, Springfield, Ohio (a Federally-Qualified Health Center). The inclusion criteria were: age 18 or older, insured by either Medicaid or Medicare Part D, eligible for MTM services (as identified through the OutcomesMTM platform), and had never previously received an MTM service. A list of eligible patients was obtained $(n=389)$ and called over the telephone using a pre-formatted calling script. Verbal consent to participate in the study was obtained during this phone call.

After verbal consent, participants were distributed to the inperson education or brochure group based on their ability and willingness to attend the in-person educational event. Individuals were first asked if they were willing to attend the in-person education. If not, they were asked if they were willing to receive an educational brochure in the mail. Those individuals not willing to attend an educational event or receive an informational brochure in the mail were excluded. In addition, those individuals who initially indicated they would attend the in-person education but did not attend were called over the telephone and asked if they were willing to receive the brochure in the mail. If they were willing, they were switched to the brochure group.

During the initial telephone call, those individuals who agreed to participate in the study received instructions appropriate to the intervention group to which they were assigned. For the in-person education, individuals were instructed over the phone of the time, date, location, and specific activities of the interactive event they would be attending. For the brochure group, individuals were informed that they would receive a pre-survey and informational brochure in the mail along with a return envelope in which to return the completed presurvey.

\section{Educational Interventions}

Although patients in different groups received education on MTM services in different educational formats, the core information about MTM services presented remained the same. Both the in-person education and brochure were designed to clearly convey the basics of MTM, an overview of patient benefits, the role of the pharmacist in MTM, and how to become enrolled in an MTM service. ${ }^{19}$ The Ohio Pharmacists Association and other pharmacy literature were used as a resource for this educational content. While the same information was being conveyed in both intervention groups, the presentation of information was very different for the intervention groups. The in-person education included a presenter, face-to-face interaction, visual aids, and time for questions. The informational brochure included factual information formatted with visuals to aid in clarity.

Participants in the in-person education group were notified of the time and date of event during the initial recruitment phone call and were mailed a "save the date" postcard with information about the event, including time and date. A week prior to the event, all participants received another phone call to remind them of the time and location of the event and verify their attendance. In addition, a lunch was advertised and provided at the event to increase participant attendance. Participants completed a pre-survey at the beginning of the educational event. The education session was approximately 30 minutes in length.

For those participants in the brochure group, the educational information was provided in a brochure distributed by mail. If the participant agreed to the study, they were sent the brochure and the pre-survey. Participants were instructed to complete the pre-survey, then read the brochure. This mailing also included a stamped, pre-addressed return envelope in which to mail back the completed pre-survey. After three weeks, those participants who still had not mailed back the pre-survey were called over the telephone to be reminded and sent a replacement survey with brochure in the mail. This was repeated after another three weeks if participants still had not responded. This method of reminding participants is based loosely on the Dillman method to maximize responses. ${ }^{20}$

All participants then completed a post-survey one month after receiving the brochure or completing the educational event with the same mailing procedure (stamped, pre-addressed envelope, with reminders). Figure 1 summarizes our process of participant recruitment, interventions, and data collection.

\section{Instruments}

First, relevant literature was examined to create the surveys. ${ }^{16,17}$ Before finalizing the survey content, it was reviewed for face and content validity. All surveys included instructions for completion that were developed specifically for either the brochure group or the in-person education group. The pre- and post-surveys had identical question content, with the exception of post-surveys having one additional question regarding patient enrollment in an MTM service. Surveys included 10 close-ended questions and 165 point, Likert-type questions ( $1=$ Strongly Disagree, 5=Strongly Agree). Cronbach's alpha for the surveys was 0.950, indicating good internal consistency. The survey instrument can be found in Appendix 1. 


\section{Data Analysis}

All data collected through pre-and post-survey results was stored in password-protected Excel spreadsheets. IBM SPSS v. 24.0 (Armonk, NY) was used to perform analyses, with all analyses based upon an alpha priori $\alpha$ value of 0.05 and a beta value of 0.8. Descriptive statistics were performed for all items. Wilcoxon Signed-Rank tests were used to examine changes in patient perceptions of MTM within groups, as appropriate. Mann Whitney-U tests and chi-squared tests were used to compare groups on perceptions of MTM, enrollment in MTM, or demographic characteristics, as appropriate.

\section{RESULTS}

A total of 35 participants completed the pre-education survey, with 10 in the in-person education group and 25 in the brochure group (Table 1). Most participants were between the ages of 45-54, female, Caucasian, had Medicaid insurance, and had a high school/GED degree or less. However, the in-person education group had a statistically significant $(p<0.05)$ higher percentage of participants with some college education or higher. All participants made less than $\$ 30,000$ a year. Lastly, most patients had not or were unsure if they had heard of MTM and had no knowledge that MTM services were fully covered by their insurance provider.

There were no significant within-group differences for the brochure or in-person education groups. , but there were significant between-group differences $(p<0.05)$ on 11 postassessment questions (Table 2).

Table 3 displays the differences within the two groups for preand post-question responses. Neither group showed significant differences between their pre-survey and postsurvey responses within their group ( $p>0.05$ ). Table 4 shows the number of participants that enrolled in an MTM service after the intervention. All in-person education participants who completed the assessments enrolled in MTM services, while no participants in the brochure group enrolled $(p<0.001)$.

\section{DISCUSSION}

Results from our pre-post observational study serve to build upon previous research regarding patients' perceptions and expectations about MTM services. Previous studies have shown that Medicare Part D enrollees who are eligible for MTM are widely unaware of the service. A study that administered surveys to 81 enrollees at four community pharmacies reported that $60 \%$ of respondents had never even heard of MTM services and $80-86 \%$ had never received MTM service components (medication therapy review, personal medication record, medication action plan). ${ }^{17} \mathrm{~A}$ second study that surveyed 504 Medicare Part D enrollees found that $93 \%$ of respondents were unaware of MTM services. ${ }^{16}$ Data from our surveys aligns well with this finding as $94.2 \%$ of our respondents were either unsure if they had heard of MTM (17.1\%) or had never heard of MTM (77.1\%).

Both of these aforementioned studies surveying perceptions of Medicare Part D enrollees on MTM services also concluded that more education efforts are needed to educate the public about MTM and its benefits. Truong et al. even suggested brochures as a potential educational intervention as $50 \%$ of their survey respondents indicated that they would like to receive brochures or talk to their pharmacists to learn more about MTM. ${ }^{17}$ This reflects that patient desires do not always align with what is actually beneficial, as the findings of our study did not show that brochures were an effective educational method for educating patients on MTM. Huet et al. assessed the impact of passive and active promotional strategies on patient enrollment in MTM. Passive strategies included distribution of bag stuffers and mailed letters, and active strategies included face-to-face offers and telephone calls. While telephone calls resulted in the most amount of respondents participating in an MTM with a pharmacist, no significant differences between the four strategies was detected. ${ }^{18}$

As previous research exposes the need for greater education of payers regarding MTM and inconclusive results as to effective means of education, our study served to help fill this gap by comparing personal and impersonal educational interventions. Findings from our data analysis indicated that while there were no significant differences within the two groups regarding differences in the pre- and post-surveys, the in-person education group reported significant differences in 11 post-survey questions all showing changes from disagreement toward neutral or agreement. These differences included increased familiarity with MTM, stronger agreement with beliefs that MTM is beneficial, increased awareness of how to enroll in MTM, and increased likelihood of enrolling in MTM in the future. Not only did those individuals in the inperson education group report increased positive perceptions of MTM, this group also had significantly increased actual enrollment in MTM compared to the brochure intervention group. This finding builds upon the results of Huet et al. as we were able to show significantly increased patient enrollment in MTM with in-person education, whereas Huet et al. was unable to detect a significant difference of passive and active promotional strategies on MTM enrollment. ${ }^{18}$

These results support the finding that the impersonal brochure intervention was a less effective means of educating participants about MTM and impacting their enrollment of MTM. This is supported by results of a similar study performed in a TriCare beneficiary population that used mailing as a means of requesting participation in a medication review. Only 
$15.7 \%$ of their sample consented to participate in a medication review, and of these, only $9.7 \%$ returned a completed survey following the review. ${ }^{21}$ This strengthens the conclusion that using informational mailings as a means to garner MTM participation is not an effective use of resources.

\section{LIMITATIONS}

The main limitation of this study was a small sample size due to low respondent rates. Only a small portion of patients contacted were willing to consider participation in either intervention. Furthermore, those who agreed to participate largely did not return both required surveys and so could not be included in data analysis. The low response rate can partially be explained by the low economic level of our sample population with potentially unreliable access to phone and mailing services, which were used as the primary means of communication in our study. A different means of contacting patients may have provided for a larger sample. To minimize this problem of low sample size, participants in the education group were provided with the incentive of lunch as well as multiple reminders to attend the educational session, and participants in both intervention groups were called multiple times to remind them to return surveys. Offering the lunch could create bias for the in-person event, but despite these measures, overall participation and response rates were still low. The low respondent rates may also reflect a general lack of awareness about MTM and its impact on the initial willingness of patients to learn about MTM services.

Use of a convenience sampling method subjects the findings to potential bias. Those patients who were willing to attend an educational event may have also been more likely to enroll in MTM services. In addition, there was a baseline difference in education between the education and brochure groups, as the greatest percentage of the education group (60\%) had received some college education and the greatest percentage of the brochure group (64\%) had only achieved a high school education or equivalent. This may have impacted the differences detected between groups regarding perceptions of and enrollment in MTM. The patient demographic was mainly Caucasian women from the Springfield, $\mathrm{OH}$ region limiting the generalizability of our results.

\section{Lessons Learned}

Overall, the means of patient recruitment and data collection in this study were not very efficient with respect to cost, time, or outcomes. A large amount of time and resources were used making phone calls and managing mailings to a largely nonresponsive sample population. Participant retention was a major obstacle as only 19 of the initial 389 eligible patients (4.9\%) completed all assessments. This exposes the need for an alternative method of recruiting patients and collecting results. The methods of survey distribution could be employed including e-mail or Internet surveys, but some study populations may have limited access, such as the population utilized in this study. Other educational strategies could be utilized in the future including dispersion of information using social media, educational posters posted in pharmacies, or even educating healthcare providers rather than patients so providers could refer their patients to an MTM service.

\section{CONCLUSIONS}

Results from this study help confirm the large patient unawareness of MTM services and need for greater education to increase awareness. These findings show that educating people in a personal face-to-face context had a more positive impact on perceptions of MTM and enrollment in MTM than through an impersonal education brochure. However, more research is needed to solidify these findings as previous literature is inconclusive in regards to best education methods, and this research was limited by a small sample size and low respondent rates. Areas of future research relevant to this topic include repeating this study using an alternative form of patient recruitment and data collection to increase the sample size, evaluating other forms of educational methods such as social media, educational posters, or direct education of health care providers, and measuring perceptions of MTM after patients participate in the service.

Acknowledgements: Assistance for this project was provided by The Rocking Horse Center of Springfield, $\mathrm{OH}$ and Andrew Straw, PharmD. Thank you also to Ginger Cameron, PhD, and Stephen Yeboah for their assistance in this project.

Funding: This project was funded by an internal grant from Cedarville University School of Pharmacy.

Conflicts of Interest: We declare no conflicts of interest or financial interests that the authors or members of their immediate families have in any product or service discussed in the manuscript, including grants (pending or received), employment, gifts, stock holdings or options, honoraria, consultancies, expert testimony, patents and royalties.

Treatment of Human Subjects: IRB review/approval required and obtained. 


\section{REFERENCES}

1. Nichols-English G, Poirier S. Optimizing adherence to pharmaceutical care plans. J Am Pharm Assoc (Wash). 2000;40(4):475-485.

2. Benjamin RM. Medication adherence: Helping patients take their medicines as directed. Public Health Rep. 2012;127(1):2-3.

3. DiMatteo MR. Patient adherence to pharmacotherapy: The importance of effective communication. Formulary. 1995;30(10):596598,601-602,605.

4. Vermeire E, Hearnshaw H, Van Royen P, Denekens J. Patient adherence to treatment: Three decades of research. a comprehensive review. J Clin Pharm Ther. 2001;26(5):331-342.

5. Morris LS, Schulz R. Patient compliance-an overview. J Clin Pharm Ther. 1992;17(5):283-295.

6. Wooldridge K, Schnipper JL, Goggins K, Dittus RS, Kripilani S. Refractory primary medication nonadherence: Prevalence and predictors after pharmacist counseling at hospital discharge. J Hosp Med. 2016;11(1):48-51.

7. Raynor D. Patient compliance: The pharmacist's role. Int J of Pharm Pract. 1992;1(3):126-135.

8. Piette JD, Heisler M, Wagner TH. Cost-related medication underuse among chronically ill adults: the treatments people forgo, how often, and who is at risk. Am J Public Health. 2004;94(10):1782-1787.

9. Schommer J, Planas L, Johnson K, Doucette W. Pharmacist-provided medication therapy management (part 2): Payer perspectives in 2007. J Am Pharm Assoc. 2008;48(4):478-486.

10. Hui RL, Yamada BD, Spence MM, Jeong EW, Chan J. Impact of a medicare MTM program: Evaluating clinical and economic outcomes. Am J Manag Care. 2014;20(2):e43-e51.

11. Lau DT, Briesacher BA, Touchette DR, Stubbings J, Ng $\mathrm{JH}$. Medicare Part $\mathrm{D}$ and quality of prescription medication use in older adults. Drugs Aging. 2011;28(10):797-807.

12. Pellegrino AN, Martin MT, Tilton JJ, Touchette DR. Medication Therapy Management services: Definitions and outcomes. Drugs. 2009;69(4):393406.

13. Murray MD, Young J, Hoke $S$, et al. Pharmacist intervention to improve medication adherence in heart failure: A randomized trial. Ann Intern Med. 2007;146(10):714-725.

14. Branham A, Moose J, Ferreri S. Retrospective analysis of medication adherence and cost following Medication Therapy Management. Inov Pharm. 2010;1(1):1-8.
15. Kucukarslan SN., Hagan AM, Shimp LA, Gaither CA, Lewis NJW. Integrating Medication Therapy Management in the primary care medical home: $A$ review of randomized controlled trials. Am J Health Syst Pharm. 2011;68(4):335-345.

16. Law AV, Okamoto MP, Brock K. Perceptions of Medicare Part D enrollees about pharmacists and their role as providers of Medication Therapy Management. J Am Pharm Assoc. 2008;48(5):648653.

17. Truong HA, Layson-Wolf $C$, de Bittner MR, Owen JA, Haupt S. Perceptions of patients on Medicare Part D Medication Therapy Management services. J Am Pharm Assoc. 2009;49(3):392-398.

18. Huet AL, Frail CK, Lake LM, Snyder ME. Impact of passive and active promotional strategies on patient acceptance of Medication Therapy Management services. J Am Pharm Assoc. 2015;55(2):178-181.

19. Ohio Pharmacists Association. Medication Therapy Management services: What does it all mean? [PowerPoint].

20. Dillman DA, Phelps G, Tortora R, et al. Response rate and measurement differences in mixed-mode surveys using mail, telephone, interactive voice response (IVR) and the Internet. Soc Sci Res. 2009;38(1):1-18.

21. Linton A, Bacon TA, Trice S, et al. Results from a mailed promotion of medication reviews among Department of Defense beneficiaries receiving 10 or more chronic medications. J Manag Care Pharm. 2010;16:578-592. 
Table 1. Demographics of Participants, $n=35$ (\%)

\begin{tabular}{|c|c|c|c|c|}
\hline Demographic & $\begin{array}{c}\text { Percentage } \\
\text { (In-Person Education } \\
\text { Group } n=10 \text { ) }\end{array}$ & $\begin{array}{c}\text { Percentage } \\
\text { (Brochure Group } \\
n=25 \text { ) }\end{array}$ & $\begin{array}{l}\text { Percentage } \\
\text { (Total } n=35)\end{array}$ & $p$-value \\
\hline Age (y) & & & & 0.198 \\
\hline $25-34$ & $1(10 \%)$ & $3(12 \%)$ & $4(11.4 \%)$ & \\
\hline $35-44$ & $2(20 \%)$ & $2(8 \%)$ & $4(11.4 \%)$ & \\
\hline $45-54$ & $6(60 \%)$ & $10(40 \%)$ & $16(45.7 \%)$ & \\
\hline $55-64$ & $1(10 \%)$ & $10(40 \%)$ & $11(31.4 \%)$ & \\
\hline Gender & & & & 0.653 \\
\hline Male & $1(10 \%)$ & $5(20 \%)$ & $6(17.1 \%)$ & \\
\hline Female & $9(90 \%)$ & $20(80 \%)$ & $29(82.9 \%)$ & \\
\hline Race/Ethnicity & & & & 0.321 \\
\hline African American & $3(30 \%)$ & $4(16 \%)$ & $7(20 \%)$ & \\
\hline Caucasian & $7(70 \%)$ & $18(72 \%)$ & $25(71.4 \%)$ & \\
\hline Decline to Answer & -- & $3(12 \%)$ & $3(8.6 \%)$ & \\
\hline Level of Education & & & & 0.015 \\
\hline Less than High School & $1(10 \%)$ & $3(12 \%)$ & $4(11.4 \%)$ & \\
\hline High School/GED & $1(10 \%)$ & $16(64 \%)$ & $17(48.6 \%)$ & \\
\hline Some College & $6(60 \%)$ & $5(20 \%)$ & $11(31.4 \%)$ & \\
\hline $\begin{array}{l}\text { Two-Year College Degree } \\
\text { (Associate's) }\end{array}$ & $2(20 \%)$ & $1(4 \%)$ & $3(8.6 \%)$ & \\
\hline Household Yearly Income & & & & 1.000 \\
\hline$<\$ 30,000$ & $9(90 \%)$ & $25(100 \%)$ & $34(97.1 \%)$ & \\
\hline Missing & $1(10 \%)$ & -- & $1(2.9 \%)$ & \\
\hline Healthcare Professional & & & & 1.000 \\
\hline No & $10(100 \%)$ & $24(96 \%)$ & $1(97.1 \%)$ & \\
\hline Missing & -- & $1(4 \%)$ & $1(2.9 \%)$ & \\
\hline
\end{tabular}




\begin{tabular}{|c|c|c|c|c|}
\hline \multicolumn{4}{|l|}{ Insurance } & \multirow[t]{2}{*}{0.872} \\
\hline Medicare only & $1(10 \%)$ & -- & $1(2.9 \%)$ & \\
\hline Medicaid only (e.g. Caresource) & $8(80 \%)$ & $24(96 \%)$ & $32(91.4 \%)$ & \\
\hline Other & $1(10 \%)$ & $1(4 \%)$ & $2(5.7 \%)$ & \\
\hline Heard of MTM & & & & 0.517 \\
\hline Yes & -- & $2(8 \%)$ & $2(5.7 \%)$ & \\
\hline No & $8(80 \%)$ & $19(76 \%)$ & $27(77.1 \%)$ & \\
\hline Unsure & $2(20 \%)$ & $4(16 \%)$ & $6(17.1 \%)$ & \\
\hline \multicolumn{4}{|c|}{ Knowledge of Eligibility for Free MTM Coverage through Insurance } & 0.604 \\
\hline Yes & $1(10 \%)$ & $2(8 \%)$ & $3(8.6 \%)$ & \\
\hline No & $4(40 \%)$ & $8(32 \%)$ & $12(34.3 \%)$ & \\
\hline Unsure & $5(50 \%)$ & $15(60 \%)$ & $20(57.1 \%)$ & \\
\hline
\end{tabular}


Table 2. Differences Between Groups for Pre and Post-Survey Responses on their Knowledge and Perceptions of MTM Services

\begin{tabular}{|c|c|c|c|c|c|c|}
\hline \multirow[b]{2}{*}{ Items $^{\mathrm{a}}$} & \multicolumn{2}{|c|}{ Pre-Test } & \multicolumn{2}{|c|}{ Post-Test } & \multirow{2}{*}{$\begin{array}{c}\text { Education vs. } \\
\text { Brochure } \\
\text { Pre-test } \\
\text { p-value }\end{array}$} & \multirow{2}{*}{$\begin{array}{c}\text { Education vs. } \\
\text { Brochure Post- } \\
\text { test } \\
\text { p-value }\end{array}$} \\
\hline & $\begin{array}{l}\text { Education } \\
\text { Group } \\
\text { Median }\end{array}$ & $\begin{array}{l}\text { Brochure } \\
\text { Group } \\
\text { Median }\end{array}$ & $\begin{array}{l}\text { Education } \\
\text { Group } \\
\text { Median }\end{array}$ & $\begin{array}{l}\text { Brochure } \\
\text { Group } \\
\text { Median }\end{array}$ & & \\
\hline $\begin{array}{l}\text { 1. I am familiar with what } \\
\text { an MTM service is. }\end{array}$ & 1 & 1 & 3 & 1.5 & 0.254 & 0.047 \\
\hline $\begin{array}{l}\text { 2. I am familiar with the } \\
\text { different parts involved } \\
\text { with MTM services. }\end{array}$ & 1 & 1 & 3 & 1 & 0.341 & 0.014 \\
\hline $\begin{array}{l}\text { 3. I am familiar with who } \\
\text { provides MTM services. }\end{array}$ & 1 & 1 & 3 & 1 & 0.090 & 0.014 \\
\hline $\begin{array}{l}\text { 4. I am familiar with the } \\
\text { term Personal Medication } \\
\text { Record (PMR). }\end{array}$ & 2 & 2 & 3 & 2 & 0.627 & 0.064 \\
\hline $\begin{array}{l}\text { 5. I am familiar with the } \\
\text { term Medication Action } \\
\text { Plan (MAP). }\end{array}$ & 1 & 1 & 3 & 1 & 0.303 & 0.033 \\
\hline $\begin{array}{l}\text { 6. My current health } \\
\text { condition makes me a } \\
\text { good candidate for MTM } \\
\text { services. }\end{array}$ & 2 & 2 & 3 & 2 & 1.000 & 0.047 \\
\hline $\begin{array}{l}\text { 7. Using MTM services } \\
\text { would help me get the } \\
\text { most out of my } \\
\text { medications. }\end{array}$ & 2 & 2 & 3 & 2 & 0.815 & 0.047 \\
\hline $\begin{array}{l}\text { 8. Using MTM services } \\
\text { would help save me } \\
\text { money on my } \\
\text { medications. }\end{array}$ & 2 & 2 & 3 & 2 & 0.969 & 0.254 \\
\hline $\begin{array}{l}\text { 9. Using MTM services } \\
\text { could keep me from } \\
\text { having to go to the } \\
\text { hospital. }\end{array}$ & 2 & 2 & 2 & 2 & 0.602 & 0.875 \\
\hline $\begin{array}{l}\text { 10. Using MTM services } \\
\text { would help make sure } \\
\text { that I am taking all of my } \\
\text { medications safely. }\end{array}$ & 2 & 2 & 4 & 3 & 0.553 & 0.023 \\
\hline
\end{tabular}




\begin{tabular}{|c|c|c|c|c|c|c|}
\hline $\begin{array}{l}\text { 11. Using MTM services } \\
\text { would help make sure } \\
\text { that I am taking all of my } \\
\text { medications correctly. }\end{array}$ & 2 & 2 & 4 & 2 & 0.872 & 0.014 \\
\hline $\begin{array}{l}\text { 12. Using MTM services } \\
\text { would benefit my health } \\
\text { condition overall. }\end{array}$ & 2 & 2 & 3 & 2 & 0.679 & 0.303 \\
\hline $\begin{array}{l}\text { 13. I know how to sign up } \\
\text { for MTM services if I } \\
\text { would want to. }\end{array}$ & 1 & 2 & 3 & 1.5 & 0.174 & 0.014 \\
\hline $\begin{array}{l}\text { 14. The benefits of MTM } \\
\text { services are worth having } \\
\text { to go to an appointment. }\end{array}$ & 2 & 2 & 3 & 2 & 0.928 & 0.033 \\
\hline $\begin{array}{l}\text { 15. I am likely to use } \\
\text { MTM services in the } \\
\text { future. }\end{array}$ & 2 & 2 & 3 & 2 & 0.553 & 0.033 \\
\hline
\end{tabular}

a1=Strongly Disagree, 2=Disagree, 3=Neutral, 4=Agree, 5=Strongly Agree

Statistical Test: Mann Whitney U 
Table 3. Differences Within Groups for Completed Pre- and Post-Survey Responses on their Knowledge and Perceptions of MTM Services ( $p$ value)

\begin{tabular}{|c|c|c|}
\hline Item & In-Person Education $(n=3)$ & Brochure $(n=16)$ \\
\hline Question 1 & 0.102 & 0.142 \\
\hline Question 2 & 0.109 & 0.257 \\
\hline Question 3 & 0.109 & 0.527 \\
\hline Question 4 & 0.157 & 0.942 \\
\hline Question 5 & 0.102 & 0.248 \\
\hline Question 6 & 0.102 & 0.739 \\
\hline Question 7 & 0.180 & 0.414 \\
\hline Question 8 & 0.180 & 0.084 \\
\hline Question 9 & 0.655 & 1.000 \\
\hline Question 10 & 0.102 & 0.317 \\
\hline Question 11 & 0.102 & 0.157 \\
\hline Question 12 & 0.317 & 0.705 \\
\hline Question 13 & 0.102 & 0.187 \\
\hline Question 14 & 0.102 & 1.000 \\
\hline Question 15 & 0.180 & 0.317 \\
\hline
\end{tabular}

Table 4. Report of Enrollment in MTM Service

\begin{tabular}{lccc}
\hline Response $^{a}$ & Total $(n=19)$ & In-Person Education $(n=3)$ & Brochure $(n=16)$ \\
\hline Yes & $3(16 \%)$ & $3(100 \%)$ & $0(0 \%)$ \\
\hline No & $11(58 \%)$ & $0(0 \%)$ & $11(69 \%)$ \\
\hline Unsure & $5(26 \%)$ & $0(0 \%)$ & $5(31 \%)$ \\
\hline
\end{tabular}

aSignificant difference in enrollment between in-person and brochure, as assessed by a Chi-square test, $\mathrm{p}$ value $\leq 0.001$ 
Figure 1: Flowchart of Intervention Methods

Obtain List of Eligible Patients $(n=389)$

Call to Obtain Agreement for Participation $(n=158)$

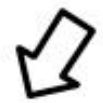

\section{In-Person Education $(n=54)$}

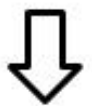

Educational Event Including Pre-Survey $(n=10)$

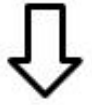

Mail \& Collect Post Surveys $(n=3)$

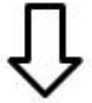

Determine Enrollment in MTM service $(n=3)$
Lost due to disconnected phone numbers unreturned phone calls, or not wanting to participate
Groups based on preference of patient

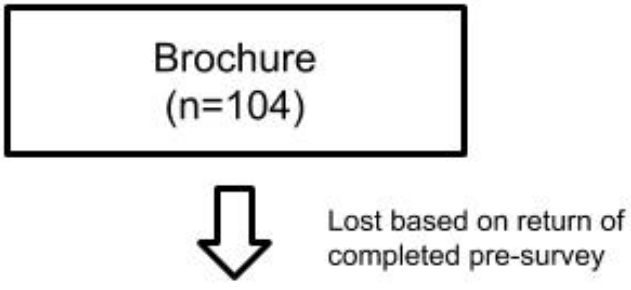

Mail Pre-Survey \& Educational Brochure $(n=25)$

Lost based on return of completed post-survey

Mail \& Collect Post Surveys $(n=16)$

Lost based on confirmation of MTM enrollment

Determine Enrollment in MTM service $(n=0)$ 